\title{
Multimodal Analysis in English Teaching Video for Pre-School Children
}

\author{
Mahsyurotun Nikmah, Universitas Airlangga
}

\begin{abstract}
The rapid development of information and communication technology renders the teaching and learning process to be easier, especially in English teaching. YouTube is one of the online websites that accommodates many videos with specific purposes and functions, including the videos of teaching English for the pre-school children. This study aims to analyze the video as the media of English teaching for pre-school children. The video analyzed in this study is taken from the channel of WOW ENGLISH TV in YouTube. By employing the multimodal analysis, this video is investigated with the theory of English teaching. Based on the investigation on the linguistics and non-linguistics aspects, the result demonstrates that the video is considered as attractive, interactive, and educative so that it is suitable to be employed for the pre-school children. This study may contribute to English teachers in teaching English to the pre-school children.
\end{abstract}

Keywords: English teaching; multimodal analysis; pre-school children; teaching video

\section{Introduction}

In this globalization era, the communication and information technologies develop over years and it covers several aspects. For instance, the people use technology to do shopping, applying for job, and also getting for information. This rapid development of technology also influences the teaching and learning process. Nowadays there are many kinds of teaching media that can be used. The website offers many interesting materials that can be used by the students which is able to use freely such as YouTube. YouTube is considered a source of online material that can play a key role in the teaching and learning field. Using YouTube videos to teach English classes as supplementary material will provide learners with good understanding and knowledge of their lectures (Almurashi, 2016).

Furthermore, the development of teaching media today become increasing from the age of pre-school up to the higher education. In recent years, the use of multimedia in conjunction with hypermedia have been successfully applied to many e-learning environments in order to both enhance these environments and to cater for a wider variety of student learning styles (Birch \& Gardiner, 2005; Sankey \& St Hill, 2009; Sprague \& Dahl 2009, Sankey, Birch, \& Gardiner, 2010).

Carey Jewitt (2009) highlights the importance of investigating intersemiotic relationships within multimodal records of teaching and learning to better understand how meaning is communicated, represented and made. Video is the main data of this work, as it provides the material and present the unique way in transferring the material of English with the communicative interactions. This phenomenon appealing the writer to analyze the video for preschool children using multimodal approach to know the meaning of the creator of video in publishing the video.

Multimodality is an inter-disciplinary research methodology that has developed over the past decade in relation to the collection, analysis of visual data, video based data, and naturally occurring digital data (e.g. CCTV, visual digital displays, online logs generated through games etc.) (Jewitt, 2009). Multimodal learning has been shown to be more effective than traditional, unimodal learning. Adding visuals to verbal (text and/or auditory) learning can result in significant gains in basic and higher-order learning (Fadel, 2008).

The previous study has been conducted by Jewitt, et al (2012) who sharing the review of the video of the digital learning environment using multimodal approaches. It is found that there are three kinds of embodiment in digital environment: physical manipulation, context and kinesthetic interaction. It also stated that there are the opportunities and challenges that faced. 
The other work has conducted by Almurashi (2016) who analyze the effective use of YouTube for teaching English as supplementary material. This work takes the sample data from 53 learners in Taibah University in Alula, Saudi Arabia. After doing the comprehensive interview and survey comments concerning the question that indicates the effectiveness of YouTube as supplementary material. It is stated that the use of YouTube in the English classes as a supplementary tool can play an important role. Additionally, the multimodal text in YouTube can play a leading role in helping learners to understand their English lessons.

This paper tends to analyze the video as the teaching media of English as Foreign Language. The video that is investigated is taken from YouTube with several criteria like the video is appropriate for pre-school children. Then it would be analyzed using multimodal approach.

\section{Method}

The source of the data is taken from one of the video that has been uploaded in YouTube. YouTube as the biggest provider of videos in the world, contain many kinds of video that could be accessed by each person and it is free. It aimed to avoid the subjective observation toward the video. The writer selects the appropriate data by using several criteria in order to create the objective research.

The video that is analyzed based on several criteria. First, the video must contain the content of English teaching for pre-school children since it is the first step that the students acquire the material of English. Second, the video must be uploaded in the nearest period in 2018. Third, the video must be viewed and watched by the highest numberof viewers. From those criteria, it is found the suitable video entitled 'Animals for Kids and Mr. Sun' that has been uploaded by WOW English TV that in March 2018 it has been viewed by more than three billion viewers.

The video has been downloaded by the writer then it has been selected the appropriate scenes that would be analyzed. The video analyzed using multimodal approach from linguistic and non-linguistic aspect. The linguistic aspect covers the methods of teaching that used by the actor in the video. While the non-linguistic aspect covers physical manipulation, context and kinesthetic interaction. Jewitt (2012) define those indicators as follows:

...Physical manipulation is how gestural interaction with artifacts shape communication and meaning in interaction... ...context define as how information is communicated between participants, focusing for example, on material sharing of Smartphone representations or through mutual gaze at aspects in the environment... ....kinesthetic interaction is a multimodal approach attends to bodily movement during interaction, as well as gesture, bodily orientation and gaze...

\section{Finding}

This work focus on two aspects that would be the indicators in analyzing the video. First, from the linguistics aspect, covers the teaching method that used by the creator and the non-linguistics aspect that covers the physical manipulation, context and kinesthetic interaction.

From the linguistic aspect, the writer found that there are some explanation that has been mentioned more than one time. It can be seen by the following utterances:

1. WIN: Oh Mister Sun, Sun,

WIN: Hello Mister Sun

WIN: Please shine down on me 


\section{Pict 1.}
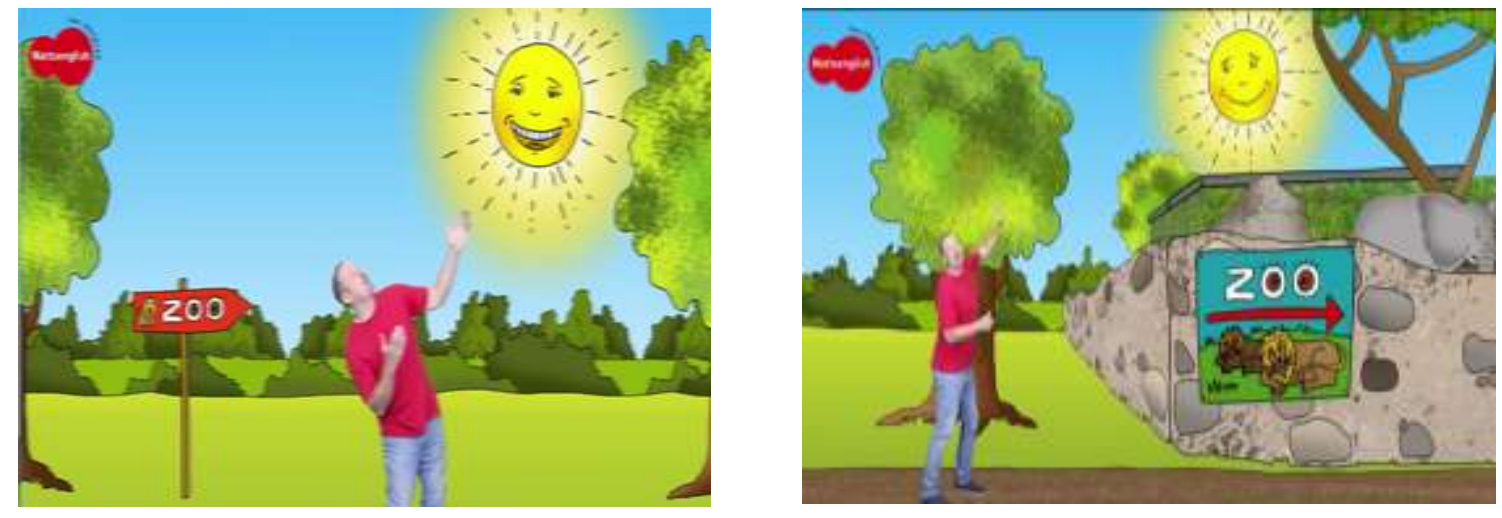

2. WIN: Oh Mister monkey, monkey WIN: Hello Mister monkey

Pict2.

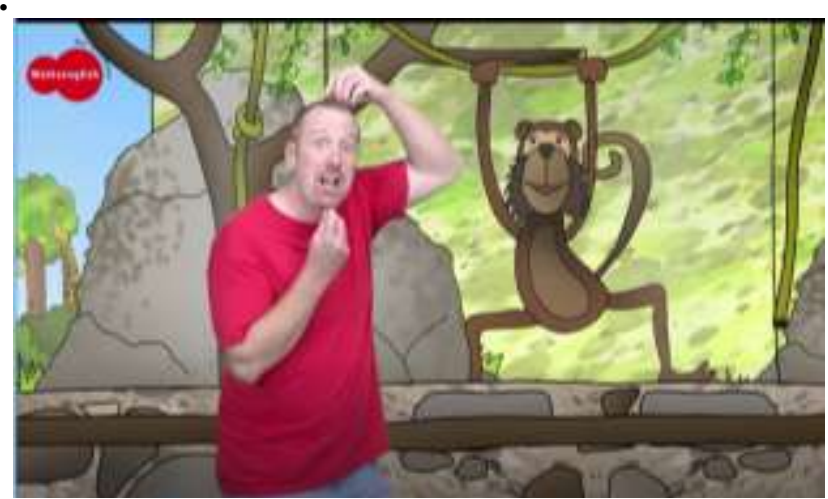

From those utterances, it can be seen that the actor repeat his statement about monkey, he repeats it 3 times. Rather than saying directly, he tries to mention it with the movement of his hand indicating the movement of monkey.

3. WIN: Looks boys and girls, it is a cheeky monkey,

WIN: say that with me, what is it?

WIN:It's a cheeky monkey, what is it?

WIN: It's a cheeky monkey, what is it?

WIN: It's a cheeky monkey

Pict3.

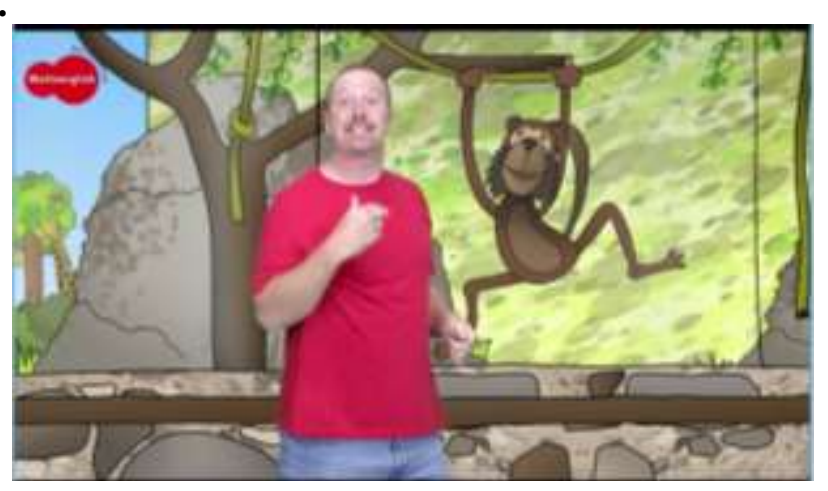

Those utterances indicating that he mention the 'cheeky monkey' 4 times. It is mentioned after the monkey is farting when he is stay beside him. That's why he calls the monkey with cheeky monkey. The cheeky monkey is mentioned 4 times is aimed to make the 
audiences are able to repeat after him. It indicates that he want to make the audience remember what he has told concerning the adjective clause. He wants to point the adjective clause of cheeky monkey to emphasize that the adjective should be placed before the noun. While in Bahasa Indonesia the adjective is must be placed after the noun. The video is really helpful to the pre-school children who acquire English as Foreign Language.

Actually he travels to the zoo and meet some animals, when he stop and meet the animal he explain about the animal then mention the adjective which represent the animals. He also uses the repetition to mention the identical adjective clause indicating the animal that he has met. Those statement above shows that the actor uses the repetition to mention the specific word or clause. It is not done with no intention, it is used to make the audiences repeat after him and remember what he has taught. Actually, it applies the theory of behaviorism which focus on the new action that used frequently until the action become automatically saved. In Guey, Cheng and Shibata (2010) stated that in stimulus-response association (S-R), classical conditioning mainly focuses on the combination of different stimuli (e.g., ringing bell and meat powder for the dog in Pavlov's classical conditioning experiment), whereas operant conditioning places the emphasis on the reinforcement posterior to the desired responses (R-R); e.g., pressing the bar followed by the reception of food as reinforcement for hungry mice in instrumental conditioning experiments (Skinner, 1935).

It also can be infer that the video also use the humanism approach indicating the method of teaching. The humanistic perspective can be characterized as mainly concerned about individual needs, values, motivations, and so on (Guey, Cheng \& Shibata, 2010). Those video tell the theme of the zoo which needed by the children who want to know the name of every animal. Sometimes the children know the animal but they could not mention the name. While the repetition also signifies the motivation that encourage the students to try to mention it again and again.

However, from the non-linguistic aspect, it covers physical manipulation, context and kinesthetic interaction. According to Jewitt (2012) the physical manipulation identified as the gestural interaction with artefacts shape communication and meaning in interaction. From the Pict 1, it clearly seen the gestural interaction of the actor. He is trying to imitate the movement of the monkey by move his one hand in above the head and the other hand under the beard. Beside that the actor always ask the audience to repeat the statement after him, or sometime he also ask the question like 'is that a lion?' It emphasizes that he wants to try to share the interactive and communicative teaching toward his audiences or his students.

From the context sides, as stated by Jewitt (2012) the context means the information is communicated between participants, focusing for example. It has been stated above that the actor meets several kinds before meeting the lion, his favorite animal. He does not only stop actually but he also explains the animal and of course giving some example of adjective clause indicating the animal, such as cheeky monkey, big elephant, noisy parrots, happy sea bear, and also sleepy lions.

Furthermore, the kinesthetic interaction is defined as bodily movement during interaction, as well as gesture, bodily orientation and gaze. It clearly seen in the video that the actor plays the body movement cleverly. In the opening of the video, he is doing the greeting to the sun. He shake his hand as indicates the greeting to the other people but actually he do greeting to the sun -that he calls it Mr. Sun. 'Oh Mr. Sun, Sun, Hello Mr. Sun, please shine down on me' this utterance complete his greeting to the sun.

He also walks around the gate of the zoo with lift his feet one side while the other feet is keep step on the ground and change the other feet to be lifted the let other side keep step on the ground. It seems implies that he enjoys the walk and love to play his foot like the children do. In other scene, he sometimes imitate the movement of the animal like put his hand in his nose and the other hand stick in front of her nose like the tusk of the elephant. In other scene, he is trying to make the lion wake up by singing in front of the lion. When the lion is roaring, his body represent afraid by exhibit his face that his eyes glared, his mouth gaping wide and his both palm open. He also run quickly to keep far from the lion although the lions is their cage. In 
addition, the gaze of the actor is really convincing the audience. He is able to glared or just glance his eyes in appropriate time. This video shows that it is really appropriate to be used by the pre-school children.

However, there are some weakness that has been found by the writer. First, there is not the subtitle in every scene of the video. Subtitle is really useful to the pre-school children to help them in acquiring the new vocabularies moreover to the student who acquire English as foreign language. It also help them to read and know the spelling of every detail of the new words that has already heard. Second, the material is supposed to explain the detail information regarding the characteristics of specific animal. It will help them to differentiate which one is cat and which one is lion. Third, the design of the animal which use the writing sketch not the real picture of the animal. It will create the confusion of the students since the size of lion is almost same with the giraffe.

\section{Conclusion}

The certain video that become the discussion in this paper is entitled Animals for Kids and Mr. Sun that has been downloaded from YouTube. The material of English for pre-school children that has shown in WOW English TV.

From both side of linguistic and non-linguistic aspect, the actor fulfills those aspects. In the linguistic aspect he use the teaching method of behaviorism and humanism by using the repetition in mention the adjective clause like cheeky monkey and it contains the motivation indirectly. Besides that the video also fulfill the criteria of physical manipulation, context and kinesthetic interaction that proposed by Jewitt (2012). It can be inferred that the video is suitable to use topre-school children since it is attractive, communicative, and interactive.

Unfortunately although the video has the excess, it also has the weakness. The weaknesses are there is not the subtitle in every scene of the video, in fact it will help the student who acquire English as foreign language know the spelling of the specific word. The other weakness is there is not the detail information regarding the characteristic of the specific animal.

\section{Transcription Key}

WIN:

speaker line

Pict

indication of screen shot

\section{References}

Almurashi, W. 2016. The effective use of youtube videos for teaching english language in classrooms as supplementary material at University in Alula. Journal of English Language and Linguistics Research. vol. 4, p. 3.

Birch, D. \& Gardiner, M. 2005. Students' perceptions of technology-based marketing courses, paper presented at the ANZMAC Conference: Broadening the Boundaries, Fremantle, Western Australia.

Fadel, C. 2008. Multimodal learning trough media: what the research says. Cisco Systems.

Guey, C.-C., Cheng, Ying-ying, \& Shibata, S. 2010. A triarchal instruction model: integration of principles from behaviorism, cognitivism, and humanism, 1-14.

Jewitt, C. 2009. Routledgehandbook of multimodal analysis. London: Routledge.

Jewitt, C., \& Sarah, P. 2012. Multimodal approaches to video analysis of digital learning environments. Proceedings of BCS HCI 2012 Workshops.

Sankey, M., \& St Hill, R. 2009. The ethics of designing for multimodality: Empowering nontraditional learners. In Demiray, U \& Sharma, R (eds.). Ethical Practices and Implications in Distance Education. London: Ideas Group International, pp. 126-155

Sankey, M., Birch, D., \& Gardiner, M. 2010. Engaging Students through multimodal learning environments: the journey continues ascilite. Sydney. 
Skinner, B. F. 1935. The generic nature of the concepts of stimulus and response. Journal of General Psychology, 9:40 - 45.

Sprague, E. W., \& Dahl, D. W. 2009. Learning to click: an evaluation of the personal response system clicker technology in introductory marketing courses. Journal of Marketing Education, 32(1), 93-103. 